\title{
POTENSI EKOWISATA BAHARI PADA PULAU-PULAU KECIL DI HALMAHERA SELATAN
}

\author{
Muhammad Agus Umar' \\ 1Fakultas Ilmu Pendidikan, Universitas Bumi Hijrah Tidore \\ Jl. Raya Sofifi, Kota Tidore Kepulauan, Provinsi Maluku Utara \\ Email : muhagus197@gmail.com
}

\begin{abstract}
Abstrak
Ekosistem pesisir memiliki potensi yang besar dan dapat dikelola untuk kepentingan kegiatan pariwisata yang dapat dterapkan dengan konsep ekoswisata. Dalam konsep ekowisata, wisata yang dilakukan memiliki bagian yang tidak terpisahkan dengan upayaupaya konservasi, pemberdayaan ekonomi lokal dan saling menghargai perbedaan kultur atau budaya. Tujuan penelitian ini adalah untuk mengetahui potensi ekowisata bahari di pulau-pulau kecil yang terdapat di wilayah Kabupaten Halmahera Selatan dan mengetahui aspek yang menjadi kekuatan untuk nantinya dapat dikembangkan sebagai kawasan ekowisata bahari. Metode yang digunakan dalam penelitian ini adalah metode survey dan penentuan titik stasiun secara purposive sampling. Hasil penelitian diperoleh nilai Indeks Kesesuaian Wisata pada stasiun I dan II masing-masing 87,14\% dan 88,57\%. Penilaian mengenai kekuatan, kelemahan, peluang, dan ancaman, pengembangan potensi pantai dinilai dari hasil pengamatan di lokasi penelitian, wawancara dan kuesioner. Pantai Pulau Sali dan Daga Besar di gugusan kepulauan Widi memiliki potensi sebagai kawasan ekowisata bahari seperti keindahan alam yang masih asli, alami dan begitu eksotis, biota laut dan terumbu karang yang beranekeragam. Aspek kekuatan yaitu pemberdayaan masyarakat lokal, peningkatan fasilitas dan prasana pendukung lain.
\end{abstract}

Kata kunci : Potensi, Ekowisata bahari, Pulau-pulau kecil

\begin{abstract}
Coastal ecosystems have great potential and can be utilized for the benefit of tourism activities that can be managed with the concept of ecotourism. In the concept of ecotourism, tourism conducted in this context has an integral part with the efforts of conservation, local economic empowerment and mutual respect for cultural differences or culture. The purpose of this study is to determine the potential of marine ecotourism on small islands contained in South Halmahera and know the aspects that become the strength to later be developed as a marine ecotourism area. The method used in this research is survey method and station point determination by purposive sampling. The result of the research shows that the Value of Travel Assessment Index at station I and II are $87.14 \%$ and $88.57 \%$, respectively. Assessment of strengths, weaknesses, opportunities, and threats, the development of coastal potential is assessed from observations at study sites, interviews and questionnaires. Sali Island Beach and Daga Besar Island Beach in the Widi archipelago have the potential as a marine ecotourism area such as natural beauty that is still original, natural and so exotic, marine biota and diverse reefs. Aspects of strength that is the empowerment of local communities, improvement of facilities and other supporting infrastructure.
\end{abstract}

Keywords: Potency, Marine Ecotourism, Small Islands 


\section{PENDAHULUAN}

Ekosistem pesisir memiliki potensi yang besar dan dapat dikelola dan dimanfaatkan untuk kegiatan pariwisata. Salah satu jenis wisata pesisir di Indoensia adalah wisata pantai. Wisata pantai merupakan suatu bentuk wisata yang dilakukan di daerah pantai yang umumnya memanfaatkan sumberdaya pantai (Putera et al., 2013).

Menurut Nurisyah (1998) dalam Rif'an (2018) wisata bahari merupakan jenis wisata minat khusus yaitu dengan mengelola dan menfaatkan bentang alam laut dan pesisir baik yang dikelola secara langsung seperti berenang, berperahu, snorkeling, diving, maupun tidak langsung seperti piknik, dan olah raga pantai.

Konsep pengelolaan wisata dalam penerapannya harus memenuhi tiga unsur keberlanjutan dalam, yaitu: (1) aspek ekologi, (2) aspek sosial, dan (3) aspek ekonomi. Dimana aspek ekologi adalah sumberdaya yang akan dikelola oleh pengembang wisata. Aspek sosial merupakan para pelaku wisata yaitu, pengelola, yang terlibat dan penikmat jasa yang memastikan wisata akan berjalan sesuai tujuan. Agar berjalan baik, wisata harus beriringan dengan aspek ekonomi melalui pendekatan industri. Salah satu bentuk produk wisata sebagai bagian dari konsep pariwisata berkelanjutan adalah konsep pengembangan ekowisata (Yulianda et al., 2010).

World Tourism Organization (2007) dalam Suma (2018) membagi destinasi pariwisata dalam enam elemen : (1) atraksi wisata (Atraction), (2) layanan dan fasilitas yang mendukung (Public and Private Amenities), (3) aksebilitas (Accesibilities), (4) Sumberdaya manusia (Human Resources), (5) keunikan dan cirri khas (Image and Character) dan (6) harga (price).

Pariwisata sebagai sub sektor ekonomi, merupakan industri terbesar dan tercepat perkembangannya di dunia. Prioritas pariwisata yang utama dan pertama adalah membangun manusianya, terutama masyakarat lokal dan yang langsung berinteraksi dengan wisatawan agar tercapai kesetaraan (Baiquni, 2010).

Kabupaten Halmahera Selatan merupakan daerah yang terletak di selatan wilayah Provinsi Maluku Utara. Secara geografis, sebagian besar wilayah kabupaten Halmahera Selatan adalah daerah kepulauan dan sekitar $80 \%$ wilayahnya adalah lautan dengan berbagai keanakeragaman hayati di dalamnya. Jumlah pulau di Kabupaten Halmahera Selatan kurang lebih 269 pulau baik yang berpenghuni maupun tidak berpenghuni. Keberadaan pulau-pulau, luasnya pesisir dan lautan disertai keragaman biodiversitasnya dapat dimanfaatkan untuk kesejahteraan masyarakat.

Oleh karena itu, kajian tentang potensi ekowisata sangat dibutuhkan untuk dijadikan sebagai salah satu solusi dan model pengelolaan pariwisata yang berkelanjutan. Penelitian ini bertujuan untuk mengetahui potensi ekowisata bahari pada pulau-pulau kecil yang terdapat di Kabupaten Halmahera Selatan dan mengetahui aspek yang menjadi kekuatan untuk nantinya dapat dikembangkan sebagai kawasan ekowisata bahari.

\section{METODE PENELITIAN}

Penelitian ini menggunakan metode survei dengan pemilihan lokasi sampling pada 2 titik yang dilakukan secara purpossive sampling. Lokasi penelitian tepatnya di Pulau Sali (stasiun I) dan Pulau Daga Besar (stasiun II) yang berada di gugusan Kepulauan Widi. Kedua lokasi ini dianggap mewakili karakteristik pulau-pulau kecil yang tesebar di wilayah Kabupaten Halmahera Selatan.

Paramater kualitas lingkungan perairan yang diukur adalah suhu, $\mathrm{pH}$ dan Salinitas menggunakan alat ukur kualitas air portable AMT03, untuk kadar oksigen terlarut menggunakan BOD dan DO meter HI98193. Sedangkan untuk pengukuran parameter kecerahan menggunakan keping secchi dan parameter sampah dilakukan dengan pengamatan secara visual di lapangan. Data hasil pengukuran parameter kualiatas lingkungan yang sudah diperoleh kemudian 
dibandingkan dengan baku mutu air laut yang terdapat dalam Keputusan Menteri Negara Lingkungan Hidup Nomor 51 Tahun 2004 tentang baku mutu air laut untuk wisata bahari.

Analisis kesesuaian wisata menggunakan matriks kesesuaian yang disusun berdasarkan kepentingan setiap parameter dengan menggunakan rumus kesesuaian wisata rekreasi pantai (Yulianda, 2007). Langkah selanjutnya adalah merumuskan strategi pengembangan ekowisata bahari yang dilakukan dengan menerapkan teknik analisis SWOT. Untuk memperoleh data pendukung analisis SWOT, penulis mencoba menggali informasi sebanyak mungkin dengan melakukan wawancara medalam kepada beberapa stake holder terkait. Pengumpulan data sekunder juga dilakukan untuk mendukung kegiatan penelitian. Setelah berbagai data diperoleh maka dilakukan analisis secara deskriptif kualitatif guna menjawab tujuan penelitian yang sudah dirumuskan.
HASIL DAN PEMBAHASAN

Profil dan Letak Geografis

a. Pulau Sali

Pulau Sali berada di wilayah Kecamatan Bacan Timur, Kabupaten Halmahera Selatan. Secara geografis, Pulau Sali terketak pada titik koordinat : LS : $0^{\circ} 25^{\prime}$ 46.23" dan BT : $127^{\circ} 44^{\prime}$ 25.09". Pulau Sali memiliki satuan bentuk lahan berbukit dan sedikit bergelombang, daratan rendah tersebar di wilayah pesisir dengan struktur tanah aluvial dan didominasi jenis tanah dystropepts yaitu jenis tanah dengan tingkat kepekaan erosi beragam. Pulau Sali merupakan salah satu pulau yang berpenghuni. Di Pulau Sali sendiri terdapat satu desa yaitu Desa Sali dengan jumlah pendukung sekitar 280 jiwa yang di dalamnya terdapat 59 kepala keluarga. Transportasi untuk menuju ke pulau ini dapat menggunakan speed boat dengan waktu tempuh perjalanan kurang lebih satu jam.

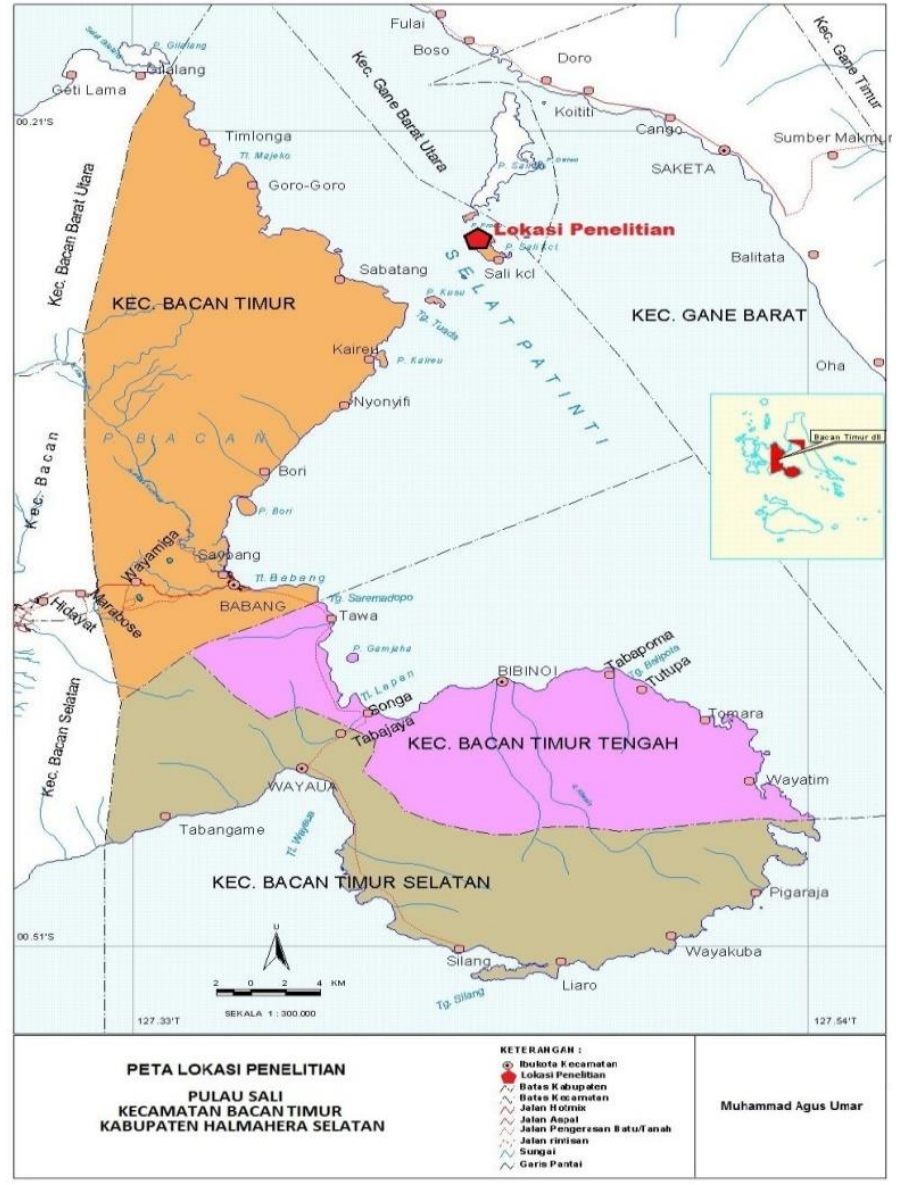

Gambar 1. Peta Lokasi Penelitian Pulau Sali Kec. Bacan Timur 


\section{b. Gugusan Kepulauan Widi}

Gugusan kepulauan Widi adalah daerah dimana terdapat sekumpulan pulau yang berjumlah sekitar tujuh belas pulau kecil yang tersebar di laut Halmahera. Secara geografis, Pulau Sali terketak pada titik koordinat : LS : $0^{\circ} 34^{\prime} 51^{\prime \prime} \mathrm{BT}: 128^{\circ} 26^{\prime} 04^{\prime \prime}$ merupakan bagian dari wilayah kecamatan Gane Timur Selatan. Dari hasil pengamatan lapangan diketahui bahwa lokasi kepulauan Widi mempunyai satuan bentuk lahan datar, dengan struktur tanah aluvial dan pasir dengan jenis tanah Troporthens yaitu jenis tanah dengan kepakaan terhadap erosi tinggi. Selain itu, dari hasil pengamatan pada peta Geologi Halmahera Selatan dapat diketahui bahwa struktur geologi berapa pulau tersusun dari batuan sedimen batu gamping dan terumbu (atol) .

Gugusan kepulauan Widi merupakan kumpulan pulau-pulau kecil yang tidak berpenghuni. Sejak dahulu pulau-pulau yang ada sering dijadikan tempat persinggahan oleh para nelayan untuk beristirahat maupun dijadikan tempat berlindung ketika cuaca buruk dan kondisi laut yang tidak bersahabat.

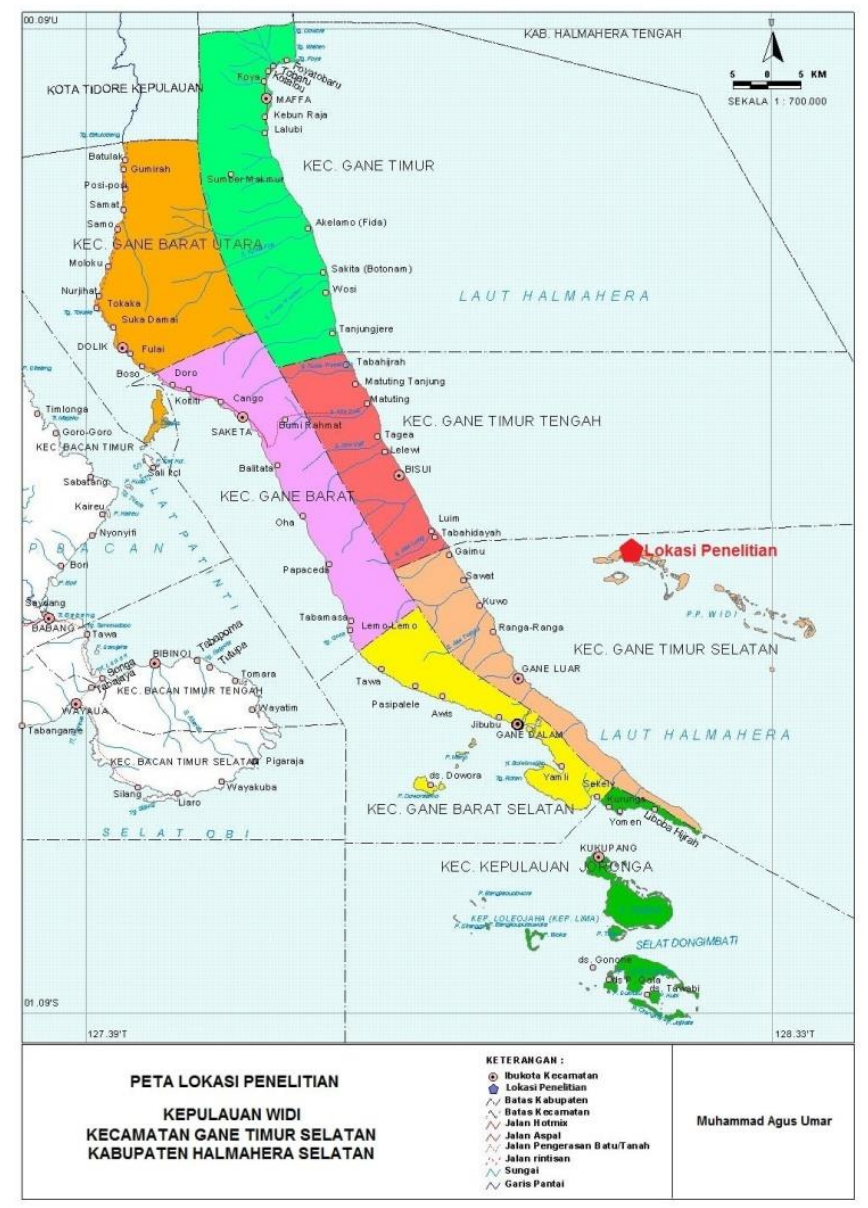

Gambar 2. Peta Lokasi Penelitian Kepulauan Widi Kec. Gane Timur Selatan

\section{Kualitas Perairan}

Kualitas lingkungan khususnya pada air laut yang diukur yaitu suhu, salinitas, kecerahan, $\mathrm{pH}$, oksigen terlarut dan keberadaan sampah. Data hasil pengukuran setiap parameter kemudian dibandingkan dengan Keputusan Menteri Negara
Lingkungan Hidup No 51 Tahun 2004 tentang baku mutu air laut untuk wisata bahari. Selain itu, penggunaan literatur lain juga dilakukan untuk mendukung dalam menganalisa data yang diperoleh. 
Tabel 1. Hasil Pengukuran Kualitas Perairan

\begin{tabular}{clccc}
\hline No & Parameter & Stasiun I & Stasiun II & $\begin{array}{c}\text { KEPMEN LH } \\
\text { No. 51Tahun 2004 }\end{array}$ \\
\hline 1 & Suhu $\left({ }^{\circ} \mathrm{C}\right)$ & 28,3 & 29,7 & Sangat Sesuai \\
2 & Salinitas & 27 & 29 & Sangat Sesuai \\
3 & Kecarahan $(\mathrm{m})$ & 3,5 & 3,9 & Sangat Sesuai \\
4 & $\mathrm{pH}$ & 7,82 & 7,69 & Sangat Sesuai \\
5 & DO $(\mathrm{mg} / \mathrm{L})$ & 6,8 & 7,2 & Sangat Sesuai \\
6 & Sampah & Tidak ada & Tidak ada & Sangat Sesuai \\
\hline
\end{tabular}

Sumber : Data Primer (2018)

\section{a. Suhu}

Suhu di laut adalah salah satu faktor penting bagi kehidupan organisme di lautan. Matahari sangat berpengaruh terhadap perubahan suhu air laut. Sejak sinar matahari diserap oleh permukaan air laut, maka lapisan ini cenderung relatif panas sampai kedalaman $200 \mathrm{~m}$ dan $1000 \mathrm{~m}$ (Hutabarat dan Evans, 2008).

Hasil pengukuran di lapangan menunjukan bahwa suhu rata-rata pada perairan di Pulau Sali adalah $28,3^{\circ} \mathrm{C}$ dan suhu rata-rata pada perairan di gugusan kepualauan Widi adalah $29,7^{\circ} \mathrm{C}$, berdasarkan KEPMEN LH No 51 maka suhu air laut pada perairan termasuk dalam kategori baik.

\section{b. Salinitas}

Menurut Boddy (1988) salinitas adalah konsentrasi total ion yang terdapat di perairan. Salinitas dipengaruhi oleh adanya proses evaporasi (penguapan) air laut, hujan, dan masukan air tawar dari sungai. Hasil yang diperoleh pada pengukuran salinitas air laut di perairan Pulau Sali sebesar 27\% sedangkan di perairan gugusan pulau Widi 29\% 00 . Menurut Efendi (2003) nilai salinitas yang baik untuk perairan laut adalah 30\% sampai $40 \%$ oo. Maka tingkat salinitas pada kedua lokasi penelitian ini termasuk dalam kategori yang baik.

\section{c. Kecerahan}

Kecerahan adalah sebagian cahaya yang diteruskan ke dalam badan air. Dari beberapa panjang gelombang di daerah spektrum yang terlihat cahaya yang melalui lapisan sekitar satu meter, jatuh agak lurus pada permukaan air (Kordi \& Tancung, 2007). Dari hasil pengukuran diperoleh data kecerahan air laut untuk perairan di Pulau Sali adalah 3,5 $\mathrm{m}$ dan pada perairan di Kepulauan Widi adalah 3,9 m. Berdasarkan Keputusan Menteri Negara Lingkungan Hidup Nomor 51 tahun 2004 tentang Baku Mutu Air Laut untuk kegiatan wisata bahari, nilai kecerahan air laut untuk kegiatan pariwisata adalah $>3 \mathrm{~m}$. Maka nilai kecerahan air laut pada kedua lokasi ini sangat sesuai untuk kegiatan pariwisata.

\section{d. $\mathrm{pH}$}

Perubahan nilai derajat keasaman $(\mathrm{pH})$ dan konsentrasi oksigen yang berperan sebagai indicator kualitas perairan dapat terjadi akibat berlimpahnya senyawasenyawa kimia baik yang bersifat polutan maupun yang bukan polutan. Limbah yang mengalir ke dalam air laut pada umumnya kaya akan bahan organik, limbah ini berasal dari berbagai macam sumber seperti limbah rumah tangga, industri pengolahan ikan maupun industri kimia lainnya. Bahan organik yang terkandung dalam limbah tersebut bisa dalam bentuk senyawa karbohidrat, protein, lemak, humus, surfaktan dan berbagai zat kimia lainnya (Susana, 2009).

Hasil pengukuran $\mathrm{pH}$ pada air laut di perairan Pulau Sali sebesar 7,82 sedangkan nilai $\mathrm{pH}$ untuk air laut di kepulauan Widi adalah 7,69. Berdasarkan Keputusan Menteri Negera Lingkungan Hidup Nomor 51 tahun 2004 tentang Baku Mutu Air Laut untuk kegiatan wisata bahari, standar $\mathrm{pH}$ air laut berkisar antara 7 
sampai 8,5. Dengan demikian maka nilai $\mathrm{pH}$ air laut pada Pulau Sali dan kepulauan Widi layak untuk kegiatan wisata bahari.

\section{e. Oksigen terlarut}

Kadar oksigen yang terlarut di perairan alami bervariasi, bergantung pada suhu, salinitas, turbelensi air, dan tekanan atmosfer. Di perairan tawar, kadar oksigen terlarut berkisar antara $15 \mathrm{mg} /$ liter pada suhu $0^{\circ} \mathrm{C}$ dan $8 \mathrm{mg} /$ liter pada suhu $25^{\circ} \mathrm{C}$, sedangkan di perairan laut berkisar antara $11 \mathrm{mg} /$ liter pada suhu $0^{\circ} \mathrm{C}$ dan $7 \mathrm{mg} /$ liter pada suhu $25^{\circ} \mathrm{C}$ (Effendi, 2003). Menurut Rochiyatun (2000) faktor yang mempengaruhi rendahnya kandungan oksigen terlarut di laut antara lain karena adanya lapisan minyak di permukaan air laut, naiknya suhu air laut, zat padat tersuspensi atau proses respirasi plankton pada malam hari.

Hasil pengukuran kadar oksigen terlarut pada perairan di Pulau Sali berada pada kisaran 6,8 $\mathrm{mg} /$ liter sedangkan di perairan kepulauan Widi berada pada kisaran 7,2 mg/liter dan sudah sesuai untuk kegiatan wisata bahari. Hal ini didasarkan pada Keputusan Menteri Negera Lingkungan Hidup Nomor 51 tahun 2004 tentang Baku Mutu Air Laut untuk kegiatan wisata bahari adalah $>5 \mathrm{mg} /$ liter sehingga perairan kedua lokasi ini sesuai untuk kegiatan wisata bahari.

\section{f. Sampah}

Pengamatan sampah dilakukan secara visual dengan melakukan pengamatan langsung di lapangan. Dari hasil pengamatan di pantai maupun perairan Pulau Sali tidak ditemukan adanya sampah yang dibuang secara sembarangan. Hal ini karena di pulau Sali sendiri hanya terdapat satu desa (Desa Sali Kecil) yang masyarakatnya masih sangat peduli terhadap lingkungan sekitar.

Kondisi yang sama juga ditemukan daerah pesisir dan perairan kepulauan Widi yag merupakan gugusan pulau kecil yang tidak berpenghuni sehingga kedua lokasi ini sangat sesuai untuk kegiatan wisata bahari dengan mengacu pada Keputusan Menteri Negera Lingkungan Hidup Nomor 51 tahun 2004 menentukan bahwa kawasan yang baik untuk kegiatan wisata bahari adalah kawasan yang tidak ada sampahnya.

\section{Indeks Kesesuaian Wisata (IKW)}

Analisis indeks kesesuaian diperlukan untuk menentukan apakah kawasan di pantai pulau Sali dan pulau kecil lain di gugusan Kepulauan Widi memenuhi ketentuan untuk wisata pantai.

Tabel 2. Indeks Kesesuaian Wisata Pantai (IKW)

\begin{tabular}{|c|c|c|c|c|c|c|}
\hline \multirow{2}{*}{ No } & \multirow{2}{*}{ Parameter } & \multicolumn{2}{|c|}{ Skor (N) } & \multirow{2}{*}{$\begin{array}{c}\text { Bobot } \\
\text { (B) }\end{array}$} & \multicolumn{2}{|c|}{ Skor Total $(\mathrm{NxB})$} \\
\hline & & I & II & & I & II \\
\hline 1. & Tipe Pantai & 3 & 3 & 5 & 15 & 15 \\
\hline 2. & Lebar Pantai & 2 & 3 & 5 & 10 & 15 \\
\hline 3. & Material Dasar Perairan & 4 & 4 & 4 & 16 & 16 \\
\hline 4. & Kecepatan Arus & 4 & 4 & 4 & 16 & 16 \\
\hline 5. & Kecerahan Perairan & 3 & 3 & 3 & 9 & 9 \\
\hline 6. & Penutupan Lahan Pantai & 4 & 3 & 3 & 12 & 9 \\
\hline 7. & Kedalaman Perairan & 4 & 4 & 5 & 20 & 20 \\
\hline 8. & Biota Berbahaya & 4 & 4 & 3 & 12 & 12 \\
\hline 9. & Ketersediaan Air Tawar & 4 & 4 & 3 & 12 & 12 \\
\hline \multicolumn{5}{|c|}{ Nilai Indeks Kesesuaian Wisata Rekreasi Pantai (Ni) } & 122 & 124 \\
\hline \multicolumn{5}{|c|}{ Nilai Maksimum IKW untuk Kegiatan Rekreasi Pantai (N maks) } & \multicolumn{2}{|c|}{140} \\
\hline \multicolumn{5}{|c|}{ \% IKW Pantai Pulau Sali dan Kepulauan Widi (Ni/Nmaks x 100 \%) } & 87.14 & 88.57 \\
\hline
\end{tabular}


Dari data pada Tabel 2 diperoleh hasil Nilai IKW tertinggi ada pada Stasiun II (pantai pulau Daga Besar) yaitu bernilai 88, $57 \%$ dan stasiun I (pantai pulau Sali) yaitu bernilai $87,14 \%$. Kedua lokasi ini termasuk kedalam kategori sangat sesuai sebagai wisata rekreasi pantai.

\section{a. Tipe Pantai}

Tipe pantai dapat ditentukan dengan melihat jenis substrat atau sedimen yang dapat dilakukan dengan mengamati langsung secara visual di lapangan. Berdasarkan pengamatan secara visual di lapangan, kawasan pantai pada stasiun I dan II terdiri atas substrat pasir putih dan berkarang sehingga kawasan ini sangat sesuai dan mendapat skor 3 .

\section{b. Lebar Pantai}

Lebar pantai sangat berkaitan dengan berapa luas areal pantai yang dapat dimanfaatkan untuk berbagai kegaiatan wisata di pantai. Pantai yang ideal untuk kegiatan wisata adalah yang datar dan landai. Kelandaian pantai cenderung mempengaruhi keamanan seseorang untuk malakukan berbagai kegiatan wisata seperti berenang, bermaim pasir, bermain ombak. Yulianda (2007) menyatakan menurut bentuknya pantai dapat dikelompokan dalam empat tipe yaitu pantai datar, landai, curam dan terjal. Hasil pengukuran lebar pantai pada stasiun I : 7,52 m, satsiun II : 12,25 m sehingga termasuk kategori sesuai dengan skor 2 untuk stasiun I dan 3 untuk stasiun II.

\section{c. Material Dasar Perairan}

Material dasar perairan/substrat merupakan faktor yang menentukan kecerahan suatu perairan. Pengamatan dilakukan dengan cara pengamatan langsung material dasar periran di lokasi penelitian. Dari pengamatan secara visual, diperoleh hasil pada stasiun I memiliki material dasar pasir berwarna putih. Kondisi yang sama juga ditemukan pada stasiun I sehingga \untuk kedua lokasi ini yaitu pantai Pulau Sali dan Pulau Daga Besar memperoleh skor 4.
Yulianda (2007) menyatakan bahwa material dasar perairan/substrat yang berwarna putih sangat sesuai untuk menunjang ekowisata pantai.

\section{d. Penutupan lahan pantai}

Adanya penutupan lahan di sepanjang areal pantai akan sangat bermanfaat bagi pengelolaan pantai untuk kegiaatan wisata pantai. Dari hasil pengamatan di lapangan, tutupan lahan pantai pada stasiun I di dominasi oleh pohon ketapang, kelapa, cemara sehingga memperoleh skor 4. Sedangkan pada stasiun II tutupan lahan pantainya berupa pohon pinus, akasia dan jenis tumbuhan ilalang serta semak. Dengan demikian maka untuk tutupan lahan pada stasiun II memperoleh skor 3.

\section{e. Kecepatan arus}

Secara umum, arus laut yang berpengaruh terhadap karakteristik perairan laut di Indonesia adalah arus laut yang dibangkitkan oleh angin dan pasut. Informasi tentang arus sangat dibutuhkan dalam berbagai macam kepentingan, seperti untuk bahan pertimbangan dalam pembangunan dermaga pelabuhan, bangunan lepas pantai maupun dekat pantai (drillingrig dan pipa-pipa yang akan dipasang di dasar laut), budidaya perairan dan pemilihan lokasi yang paling memungkinkan untuk pemanfaatan wilayah perairan (Sugianto, 2007).

Kecepatan arus sangat berhubungan dengan keamanan wisatawan melakukan kegiatan wisata seperti renang. Arus yang lemah sangat sesuai untuk kegiatan renang, sedangkan arus yang sangat kuat akan berpotensi menimbulkan bahaya karena dapat menyeret orang-orang yang sedang mandi atau renang di pantai.

Hasil pengamatan di lapangan, kecepatan arus untuk perairan di stasiun I adalah $0,09 \mathrm{~m} / \mathrm{s}$ dan untuk stasiun II dengan kecepatan arus 0,11 m/s. Penggolongan kecepatan arus dalam penelitian ini termasuk ke dalam jenis arus lambat sehingga memperoleh skor 4 . 
Harahap dalam Tambunan (2013) mengemukakan bahwa penggolongan kecepatan arus terdiri atas empat jenis kategori yaitu arus lambat dengan kecepatan pada kisaran 0-0,25 m/s, arus sedang dengan kecepatan pada kisaran 0,25-0,50 $\mathrm{m} / \mathrm{s}$, arus cepat dengan kecepatan pada kisaran 0,5-1 m/s dan kategori arus sangat cepat dengan kecepatan di atas $1 \mathrm{~m} / \mathrm{s}$.

\section{f. Kedalaman perairan}

Kedalaman suatu perairan laut sangat berkaitan dengan rasa aman dan nyaman para wisatawan yang berwisata di pantai. Kegiatan wisata pantai di Indonesia masih cenderung di dominasi oleh wisatawan lokal (wisata keluarga) yang menyertakan anak-anak sehingga perairan yang dalam tidak aman bagi anak-anak. Hasil pengukuran kedalaman perairan pada pantai stasiun I diperoleh $1,87 \mathrm{~m}$ dan pada stasiun II 1,35 m.

\section{g. Kecerahan perairan}

Kecerahan perairan menjadi salah satu parameter yang mendukung keindahan dari perairan dan kenyamanan bagi wisatawan dalam melakukan kegiatan wisata seperti berenang. Semakin dalam penetrasi cahaya yang masuk, akan semakin menambah keindahan pemandangan di perairan. Dari hasil pengukuran pada stasiun I deperoleh kecerahan perairan pantai berkisar pada kedalaman 3,5 $\mathrm{m}$ dan pada stasiun II berkisar 3,9 m. Berdasarkan KEPMEN LH Nomor 51 tahun 2004 tentang Baku Mutu Air Laut untuk kegiatan wisata bahari, nilai kecerahan air laut untuk kegiatan pariwisata adalah $>6 \mathrm{~m}$. Maka nilai kecerahan air laut pada kedua memperoleh skor 3.

\section{h. Biota Berbahaya}

Biota berbahaya juga merupakan faktor penting dalam wisata pantai baik untuk aktivitas rekreasi maupun berenang. Semakin sedikit biota berbahaya yang ditemukan di suatu lokasi wisata maka lokasi wisata tersebut akan semakin baik. Dari hasil pengamatan secara visual di stasiun I dan stasiun II tidak ditemukan biota berbahaya. Adapun biota yang ditemukan yaitu kepiting kecil di pasir sekitaran pantai, dan oleh karena jumlahnya yang sangat sedikit dan jarang ditemukan maka biota ini tidak berpotensi sebagai biota yang berbahaya sehingga kedua lokasi ini mendapat skor 4 .

\section{i. Ketersediaan air tawar}

Saat melakukan kegiatan wisata, ketersediaan air tawar (air bersih) sangat dibutuhkan untuk mendukung fasilitas pengelolaan maupun pelayanan wisata. Hal ini juga merupakan menjadi kriteria penilaian terhadap kelayakan prioritas pengembangan wisata pantai.

Air tawar yang terdapat dilokasi penelitian adalah jenis air tanah. Menurut Simanungkalit dan Lambotoruan (2016) air tanah merupakan sumber air tawar terbesar potensinya di daratan, yang penyebarannya ditentukan oleh faktor curah hujan, bentuk lahan, geologi dan lingkungan.

Hasil pengukuran jarak ketersediaan air tawar pada stasiun I yaitu $30 \mathrm{~m}$ dan pada stasiun II 75 m. Menurut Yulianda (2007), jarak yang sesuai untuk ketersediaan air tawar dengan lokasi wisata pantai adalah 0,5 $\mathrm{km}$. Pada stasiun II, meskipun pulau Daga Besar adalah pulau yang tidak dihuni secara menetap oleh warga tetapi terdapat sumber air tawar (sumur) yang digali oleh nelayan yang singgah di pulau ini. 


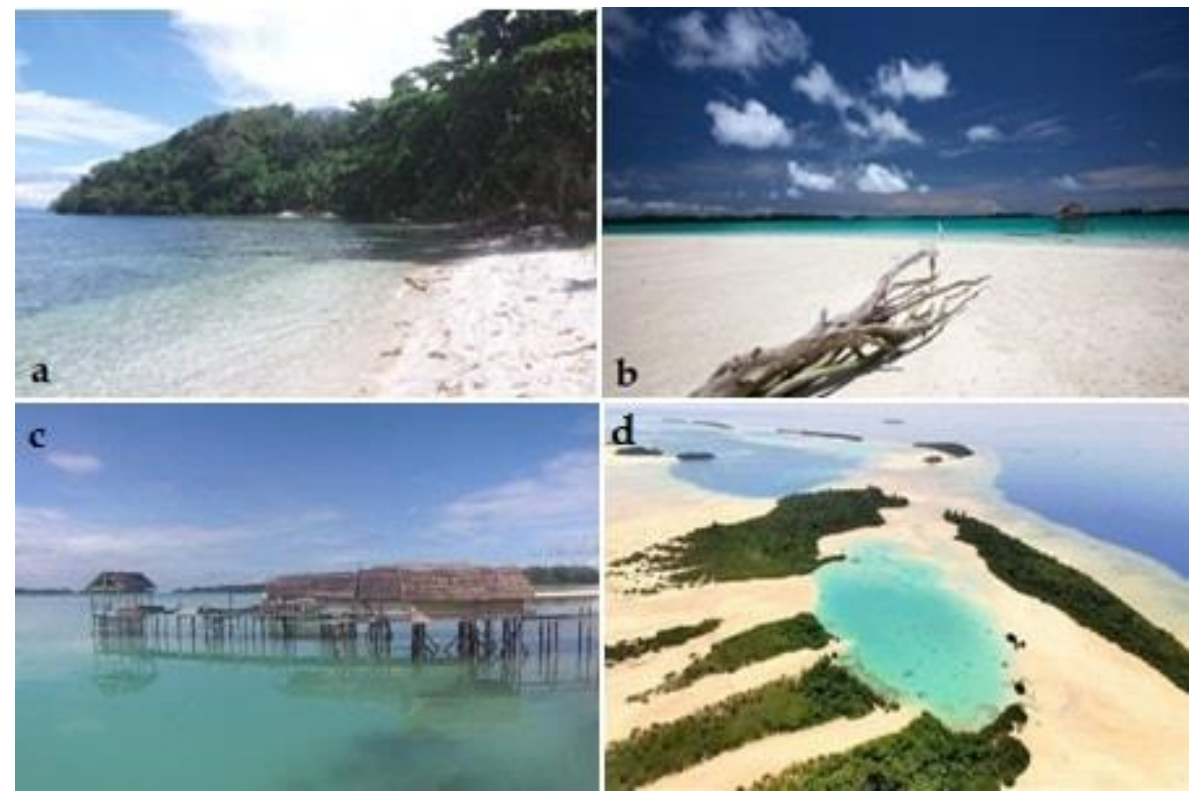

Gambar 3. pantai pulau Sali (a) pantai pulau Daga Besar (b) tempat persinggahan nelayan di kepulauan Widi (c) salah satu laguna di gugusan kepulauan Widi (d)

Potensi Ekowisata Bahari Pulau Sali dan Gugusan Kepualauan Widi

Pulau Sali memiliki keanekaragaman hayati yang tinggi baik di daerah teristerial maupun akuatik. Ekosistem hutan yang masih terjaga menjadikan pulau ini memiliki daya pikat tersendiri. Hasil oebservasi di lapangan ditemukan jenis spesies burung yang endemik seperti jenis burung Nuri Merah (Lorius garrulous) terdapat di pulau ini. Eksositem pesisir pantai dan laut di Pulau Sali meliputi terumbu karang, ikan dan megabenthos yang melimpah.

Keberadaan ekosistem dengan keanekaragaman hayati yang terdapat di dalamnya baik itu pada eksoistem darat maupun laut menjadikan Pulau Sali sangat tepat untuk dikembangkan menjadi destinasi wisata dengan konsep ekowisata. Kegiatan wisata berkonsep ekowisata seperti diving, snorkeling dan wisata ilmiah untuk kegiatan penelitian dan konservasi sangat berpotensi untuk dikembangkan di pulau ini.

Selain itu, di Pulau Sali terdapat makam yang memiliki nilai historis tinggi dan dipercaya oleh warga lokal sebagai makam keramat yang dapat dikembangkan sebagai obyek wisata religius.

Pulau-pulau kecil di gugusan kepulauan Widi juga mememiliki pontensi dan keunikan tersendiri dari ratusan pulau kecil yang ada di Kabupaten Halmahera Selatan. Dari hasil penelitian lapangan ditemukan beberapa pulau dengan karakteristik tersendiri. Pulau Dodawe Gane memiliki keunikan karena terdapat laguna di bagian tengahnya. Pulau Lolanga Kecil dan Pulau Tofuwidi terbentuk dari atol yang keberadaannya sangat dipengaruhi oleh pasang surut air laut.

Keanekaragaman hayati di gugusan kepulauan Widi juga sangat unik dan dapat dikembangakan sebagai kawasan ekowisata. Jenis burung seperti Nuri Bayan (Electus roratus), Elang laut perut putih (Haliaeetus leucogaster), Maleo (Macrochepalon maleo) ditemukan di pulau-pulau Daga Besar dan pulau-pulau lainnya. Selain itu jenis mamalia laut seperti Lumba-lumba hidung botol (Stenella longirostis) juga ditemukan di perairan gugusan kepulauan Widi sehingga menjadikan lokasi ini sangat berpotensi dikembangkan untuk kegiatan ekowisata bahari. 

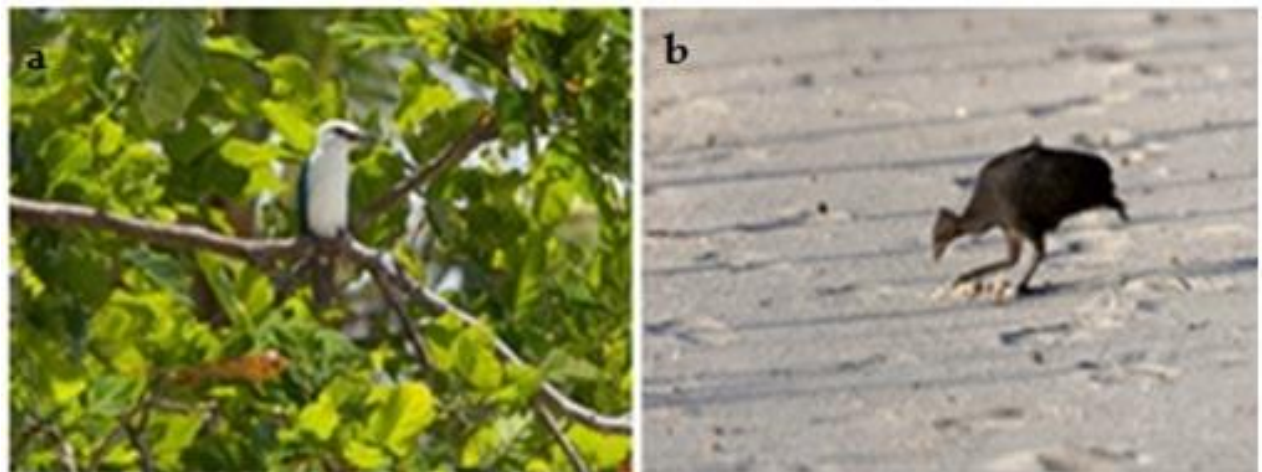

Gambar 4. Fauna di Kepulauan Widi (a dan b)

Potensi Ekowisata Bahari Pulau Sali dan Gugusan Kepualauan Widi Berdasarkan Analisis SWOT

Strategi pengembangan ekowisata bahari daerah kepualauan yang terdapat di
Kabupaten Halmahera Selatan sebagai kawasan ekowisata bahari dapat dilakukan dengan strategi SWOT sebagaimana terdapat pada Tabel 3.

Tabel 3. Strategi SWOT

\begin{tabular}{|c|c|c|}
\hline & Kekuatan (S) & Kelemahan (W) \\
\hline \multirow[t]{4}{*}{ Internal } & $\begin{array}{l}\text { Eksositem dan keanekaragaman } \\
\text { hayati darat dan laut memiliki daya } \\
\text { tarik tinggi. } \\
\text { - } \text { Memiliki niali sejarah dan religius } \\
\text { - Keramahan masyarakat lokal }\end{array}$ & $\begin{array}{l}\text { - Lemah pada fasilitas dan } \\
\text { infrastruktur pendukung } \\
\text { - Lemahnya kreatifitas dan } \\
\text { inovasi. } \\
\text { - Ketersediaan sumberdaya } \\
\text { manusia sangat terbatas }\end{array}$ \\
\hline & Strategi S-O & Strategi W-O \\
\hline & $\begin{array}{l}\text { Membangun wisata bahari dengan } \\
\text { konsep ekowisata } \\
\text { Menjadikan pantai Pulau Sali dan } \\
\text { pantai di pulau-pulau keci di } \\
\text { gugusan kepualauwan Widi sebagai } \\
\text { daerah yang minim pencemaran dan } \\
\text { pengrusakan lingkungan }\end{array}$ & 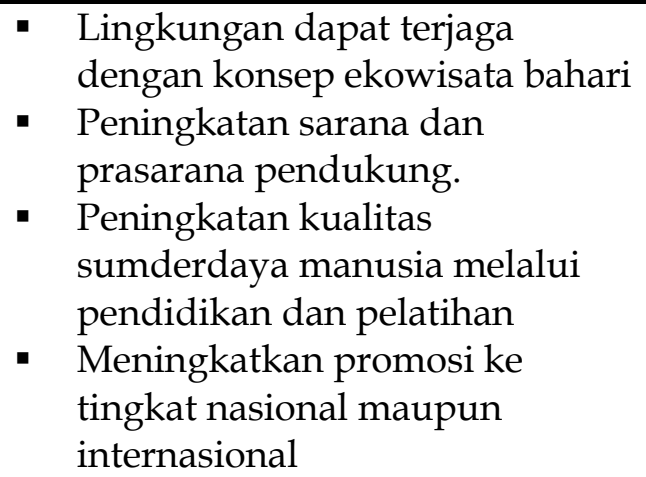 \\
\hline & $\begin{array}{r}\text { Peluang }(\mathrm{O}) \\
\end{array}$ & Ancamaman $(\mathrm{T})$ \\
\hline Eksternal & $\begin{array}{l}\text { Meningkatnya kesejahteraan } \\
\text { masyarakat } \\
\text { Meningkatnya kepedulian dan } \\
\text { komitmen pemerintah Kab. } \\
\text { Halmahera Selatan untuk } \\
\text { mengembangkan pulau-pulau kecil } \\
\text { sebagai andalan sektor pariwisata. } \\
\text { - Meningkatnya minat wisatawan } \\
\text { terhadap wisata bahari } \\
\text { Meningkatnya pengetahuan dan } \\
\text { wawasan warga masyarakat lokal. }\end{array}$ & $\begin{array}{l}\text { - Perubahan dan penurunan } \\
\text { kualitas lingkungan } \\
\text { - Perubahan nilai-nilai budaya } \\
\text { lokal } \\
\text { - Persiangan usaha kususnya pada } \\
\text { sektor pendukung kegiatan } \\
\text { pariwisata. }\end{array}$ \\
\hline
\end{tabular}




\begin{tabular}{|c|c|c|}
\hline & Kekuatan (S) & Kelemahan (W) \\
\hline & Strategi S-T & Strategi W-T \\
\hline & 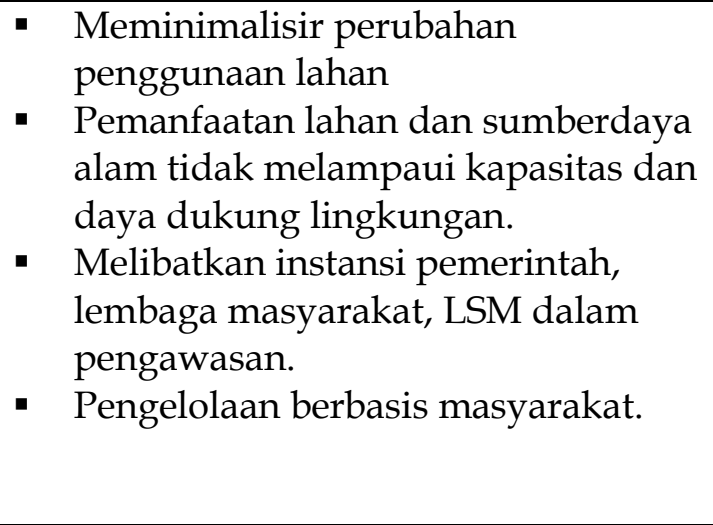 & $\begin{array}{l}\text { Penyusunan rencana tata ruang } \\
\text { daerah dan zonasi kawasan yang } \\
\text { memiliki potensi ekoswisata } \\
\text { dengan melibatkan instansi } \\
\text { terkait dan masyarakat lokal. } \\
\text { - Penegakan aturan melalui } \\
\text { peraturan daerah untuk } \\
\text { melindungi dan mencegah } \\
\text { kerusakan lingkungan pada } \\
\text { daerah-daerah yang memiliki } \\
\text { potensi wisata bahari. }\end{array}$ \\
\hline
\end{tabular}

Sumber : Data Hasil Olahan (2018)

\section{KESIMPULAN}

Pulau-pulau kecil yang terdapat di wilayah Kabupaten Halmahera Selatan memiliki potensi dan peluang besar untuk dikelola sebagai kawasan ekowisata bahari. Keanekaragaman hayati yang dimiliki baik pada ekosistem darat maupun ekosistem laut menjadikan lokasi ini sangat tepat untuk dikembangkan dengan konsep ekowisata dan konservasi.

Aspek yang menjadi kekuatan pantai Pulau Sali dan Daga Besar antara lain, pengembangan kegiatan wisata berbasis masyarakat dengan memberdayakan masyarakat lokal, kegiatan rekreasi pantai, diving, snorkeling, penelitian dan konservasi serta wisata religius. Pembangunan sarana dan prasaran pendukung seperti kafe/restaurant dan home stay sangat diperlukan untuk memberikan kenyamanan bagi wisatawan. Selain itu, srana transportasi juga harus ditingkatkan untuk memudahkan akses bagi para wisatawan untuk mencapai lokasi.

\section{UCAPAN TERIMA KASIH}

Ucapan terima kasih disampaikan kepada para pimpinan Universitas Bumi Hijrah atas dukungannya sehingga penelitian ini bisa dilaksanakan. Terima kasih juga kepada pemerintah daerah Kabupaten Halmahera Selatan khususnya kepada bapak Iksan Jasmir, S.Pi (Dinas Pariwisata) atas kesediaannya membantu penulis selama kegiatan pengambilan data di lapangan.
DAFTAR PUSTAKA

Baiquni , M. (2010). Pariwisata Berkelanjutan dalam Pusaran Krisis Global. Denpasar: Udayana University Press.

Body, C.E. (1988). Water Quality in Warmwater Fish Ponds. Fourth Printing. Aurburn University Agricultural Experiment Station. Alabama. USA.

Effendi, H. (2003). Telaah Kualitas Air Bagi Pengelolaan Sumber Daya dan Lingkungan Perairan. Yogyakarta : Kanisius

Hutabarat, S., \& S.M. Evans. (2000). Pengantar Oseanografi. Jakarta : UIPress

Kordi, M.G.H., \& A.B. Tancung. (2007). Pengelolaan Kualitas Air Dalam Budidaya Perairan. Jakarta: Rineka Cipta

Putera, A.H.F., Fachrudin, A., Niken T.M.P., \& Setyo, B.S. (2012). Kajian Keberlanjutan Pengelolaan Wisata Pantai di Pantai Pasir Putih Bira, Bulukumba, Sulawesi Selatan. Jurnal Penelitian dan Pengembangan Kepariwisataan Indonesia. Vol.8 (3) : $241-254$.

Rochyatun, E. (2000). Variasi Musiman Kandungan Oksigen Terlarut di 
Perairan Gugus Pulau Pari. Pusat Penelitian Oseanografi. LIPI. Jakarta

Simanungkalit, N.M., \& Lumbantoruan,W. (2016). Analisis Persebaran Intrusi Air Laut pada Air Tanah Freatik di Desa Rugemuk Kec. Pantai Labu Kabupaten Deli Serdang. Jurnal Geografi. 8(02), 146-155

Susana, T. (2009). Tingkat Keasaman(pH) dan Oksigen Terlarut sebagai Indikator Kualitas Perairan Sekitar Muara Cisadane, Jurnal Teknologi Lingkungan. Jakarta : LIPI.

Tambunan J.M., Anggoro S., \& Purnaweni H. (2013). Kajian Kualitas Lingkungan dan Kesesuaian Wisata Pantai Tanjung Pesona Kabupaten Bangka. Prosiding Seminar Nasional Pengelolaan Sumberdaya Alam dan Lingkungan. Magister ilmu lingkungan. Universitas Diponegoro. Semarang.

Rif'an, A.A. (2018). Daya Tarik Wisata Pantai Wediombo Sebagai Alternatif
Wisata Bahari di Daerah Istimewa Yograkarta. Jurnal Geografi. 10(1), 6373.

Suma, N.N. (2018). Informasi Geospasial Untuk Membangkitkan Potensi Wisata Pesisir Pada Jalur Lintas Selatan Jember Jawa Timur. Jurnal Geografi. 10(1), 26-41.

Tuwo, A. (2011). Pengelolaan Ekowisata Pesisir dan Laut. Brilian Internasional. Surabaya

Yulianda F., Fachrudin A., Ambrosius AH., Sri H., \& Kusharjani, Ho S K. (2010), Pengelolaan Pesisir dan Laut Secara Terpadu.

PUSDIKLAT KEHUTANAN-SECEM-KOICA. Bogor.

Yulianda, F. (2007). Ekowisata Bahari Sebagai Alternatif Pemanfaatan Sumberdaya Pesisir Berbasis Konservasi. Makalah. Departemen Manajemen Sumberdaya Perairan. Fakultas Perikanan dan Ilmu Kelautan. 